\title{
SCIENCE AND COMMUNICATION: HOW TO TRANSFER KNOWLEDGE?
}

\author{
Todar Lakhvich \\ Belarusian State Medical University, Republic of Belarus
}

There is no such thing as moral or immoral books. Books are well written or badly written. That is all.

Oscar Wild

A couple of months ago I came back to the University after vacations: well rested, full of ideas and having strong desire to tell the students everything I knew about my "beloved" organic chemistry. The counterpart was even better (in all the cases they were younger: "cela se passe de commentaries"): a large majority of the students are smart, attractive, and well put together. Just seemed to be the best time and place for effective teaching-learning (as we like to say in articles) process. As usual, I had a joy during the first lecture (feeling happy of touching once more I liked so much and engaging in my own understanding of the subject) and after the first seminar where students followed generally the logics and the way of professor thinking. However, a few days later during the classes followed by the romantic period of our acquaintance I faced the problem: the students barely understood some very easy things. Not because they didn't know, not because they were lazy, vs they could understand the more difficult things (I work at Medical University with the highest students' percentile). They couldn't understand very simple things because sometimes we were speaking in different languages. To some extent and in some cases, it's a problem of interlingual interference of the mother tongue (Chittima Kaweera, 2013): one third of my students are overseas and we need to communicate in international languages like English or Russian. But misunderstanding is taking place for communication even with native speakers: and the problems are basically the same we face with foreigners. I thought about the phenomenon for years, tried to explore the problem empirically and now I'm convinced - communication is a very complex process which consists of many subunits and some of them are within the formal command of Lexis and Grammar, without taking into account, the Context.

A few weeks ago I visited Japan for the first time. I expected to see something mysterious and different from what I used to see in Europe. I was afraid Japanese would be closed. Not at all. I liked Japan, but it's the topic for the other article. Japanese are very friendly and unexpectedly for me fond of western culture (it does not prevent them to keep their own traditions!) and open for communication. In all the situations I needed the aid, they wanted to help, to explain.... but.... Usually we faced the problem of communication. The average Japanese I met knew many English words and tried to list them when answering to my questions. But it was a great "gap" between the "object meaning", they tried to represent. It was the meaning we usually associate with nouns. We lacked "communication". I found no connection between the nouns they listed to visualize the objects. I saw no processes which were associated with verbs and attributives. Finally, while I was staying, we found the other means for understanding: gestures, signs and finally smiles))) and I had a nice time in Japan. But coming back to Minsk I thought once more about the importance of "connections", depicturing of the processes occurring between the objects. It's much easier to learn (by heart!) terms, definitions, but more important, to understand the process. In some sense it sounds like an educational paradigm.

When teaching foreign students (even, when they are speaking fluently!) I found they can't understand some word combinations we used to say from school (sometimes from kindergarten). There are basically two main reasons for such misunderstanding. The first one is connected with the specificity of the processes occurring with Science objects (better to say with models depicting the real objects). For sure, we could find no tradition in folk for visualization of chemical reaction. But people brewed beer, dyed fabrics, melted metals, kept in a pottery kiln... Chemical reactions such as combustion in the fire, fermentation and the reduction of ores to metals were known 
since antiquity (Grinev-Griniewicz, 2004). Just the reason why scientists and teachers found some verbs and attributives to visualize the behavior of Science objects. It's a question of Psycholinguistics that is interdisciplinary field having roots in Education and Philosophy (Levelt, 2013). It answers the question how people acquire process and comprehend language. In our "Science Education" context, it's interesting to compare how processes are traditionally semantically expressed in different languages. The understanding of semantics can help us to explain better the Science topics not only for foreign but native speaking students.

For example, we say the reaction proceeds or goes in English. In other languages we use the other verbs, which in literal translation will be: unroll in French, run or go in Ukrainian and Slovak, take place in Belarusian, flow in Russian and so on. Sometimes there are few accepted words; some of them are closer to other languages by meaning. However, literal calque translation can lead to misunderstanding in other languages.

The other issue is connected with Pragmatics which is a subfield of linguistics and semiotics and studies the ways in which context contributes to meaning. Just while saying "You have a red light" you are ambiguous. In different contexts it could mean that:

- you have red lighting in the garden;

- your face is red because of heart attack;

- your project was stopped and you failed to be granted;

- you have a red light while driving your car.....

Without knowing the context, it is difficult to understand the meaning with confidence. When teaching foreign students, we face with misunderstanding for classes accepted in our language. For example the word combination "distance between atoms" (very frequently used in chemistry and Physics) sounds in Russian (in literal calque translation) "distance between nuclei". In English we say (in terminology) about the "ends" of the Carbon chain and in Russian we used to differentiate the "end" and the "beginning" of the chain. There are many other examples. One can say it's a problem of command of language. But for now I'm convinced a large majority of the native speaking students learned the terms formally by heart and do not understand either object structure or processes occurring with them. To make the understanding easier, we need to introduce in Education different types of visualization, including formal techniques (model kits, computer programmes, graphic representation) and informal explanation with the aid of image visualization of known objects (Lakhvich, 2010).

For example, structural isomers can be visualized as sequence of animal toys. Structure defines the sequence of bonding and it looks like the toy animals are holding hands of each other.

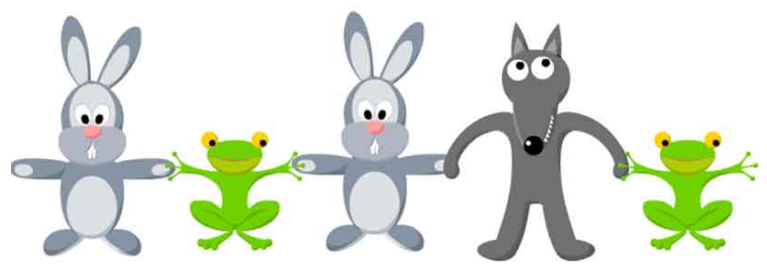

The next example defines the difference (and the process of possible transformation when heating!) between $\mathrm{E}-\mathrm{Z}$ (cis-trans) isomers.
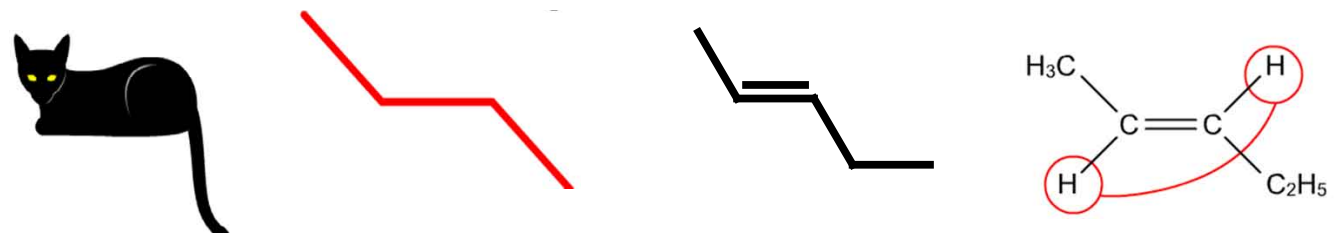

ON THE OPPOSITE SIDES 

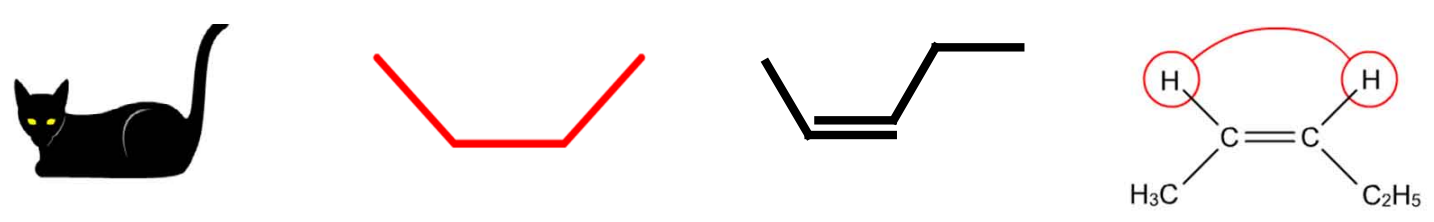

\section{ON THE SAME SIDES}

And finally we tried to visualize the process of Addition reaction by means of image and geometric types of representation followed by the final model presented by usual chemical graphical form.

IMAGE REPRESANTATION

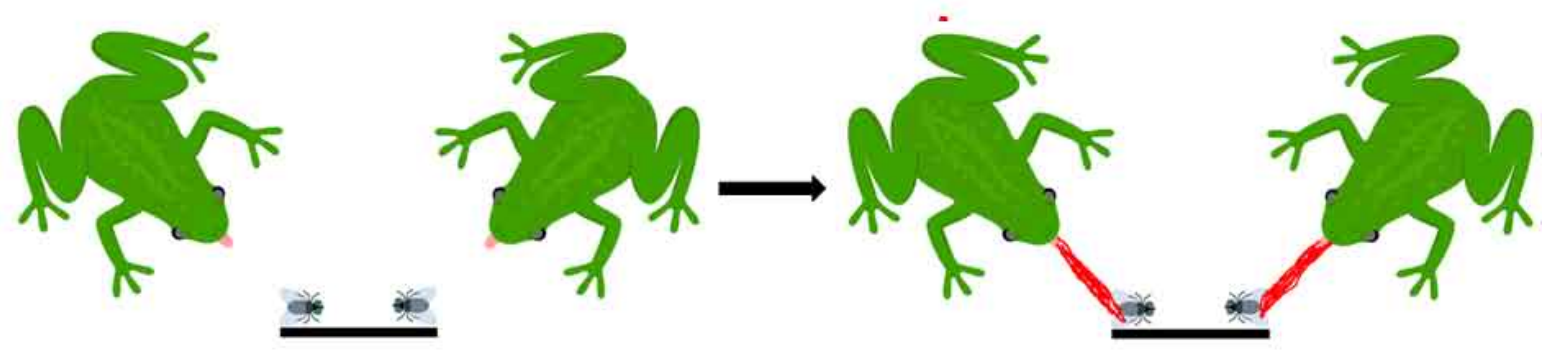

GEOMETRIC REPRESANTATION

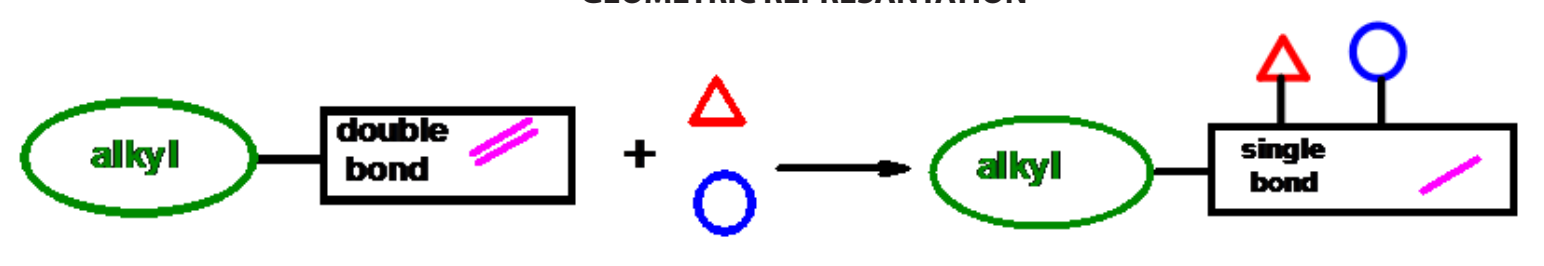

CHEMICAL REPRESANTATION

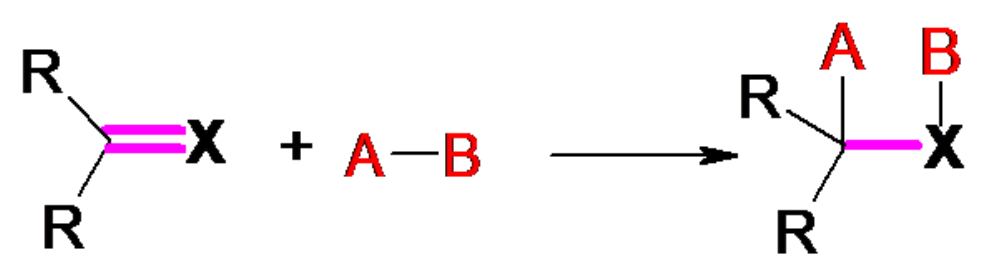

Thus, visualization with the aid of previously acquired models (known from life experience, or from the other disciplines) helps to promote the understanding process both for foreign and native speaking students.

The same is important for writing materials: taking in account not only manuals, but scientific articles as well. In this context, the formal knowledge of words and Grammar don't mean the effective intralingual transfer. And reviewing proposals in English from different countries, the members of an Editorial board face frequently the misunderstanding problem. Subject context means we should use similar models, both in Science and Education, operate with accepted language clichés related to definite field of knowledge and geographic area. When you are not a native speaker, we can advise you to avoid the odd idioms, even if they are used in your mother tongue. The shorter phrase means the better understanding. So don't be afraid to put a few simple sentences instead of one complex or even complex-compound sentence. Nobody challenges your knowledge about the usage of absolute participle construction. But we want everybody when reading the article to clearly understand what the author wanted to say.

And finally, we advise you to follow the rules for authors. We just want to repeat once again "All authors must take care of the language revision on their own. The language must be clear and accurate. The work should be written in an impersonal style. The editor reserves the right to send the manuscript to be reviewed. If English is a 
second language for the author, please consider having the manuscript proofread and edited before submitting". To comply with the requirements of scientific ethics, I give the citation to the page which regards our authors what they need to do in order we understood what they wanted to say in their proposals.

(http://www.scientiasocialis.It/pec/files/General_Requirements_PEC.2010.pdf).

\section{References}

Grinev-Griniewicz, S. (2004). Evolution of terminology and culture: Establishing foundations for anthropological linguistics. Language and culture: establishing foundations of anthropological linguistics / Edited be S. Grinev-Griniewicz, S. M. Raub, P. Thomas. - Bialystok: Bialystok Series of Anthropolinguistics, 2004, Vol. 1, p. $27-42$.

Kaweera, C. (2013). Writing error: A review of interlingual and intralingual interference EFL context. English Language Teaching, $6(7), 9-18$.

Lakhvich, T. (2010). Beautylity of chemistry visualization: Whether useful can be aesthetic science education: Search for harmony and beauty. Problems of Education in the $21^{\text {st }}$ Century, 19, 46-50.

Levelt, W. J. M. (2013). A history of psycholinguistics: The pre-Chomskyan era. Part 1. Oxford: Oxford University Press.

Received: September 30, 2014

Accepted: October 08, 2014

Todar Lakhvich

PhD., Associate Professor, Belarusian State Medical University, Minsk, Republic of Belarus.

E-mail: bntu71@gmail.com 